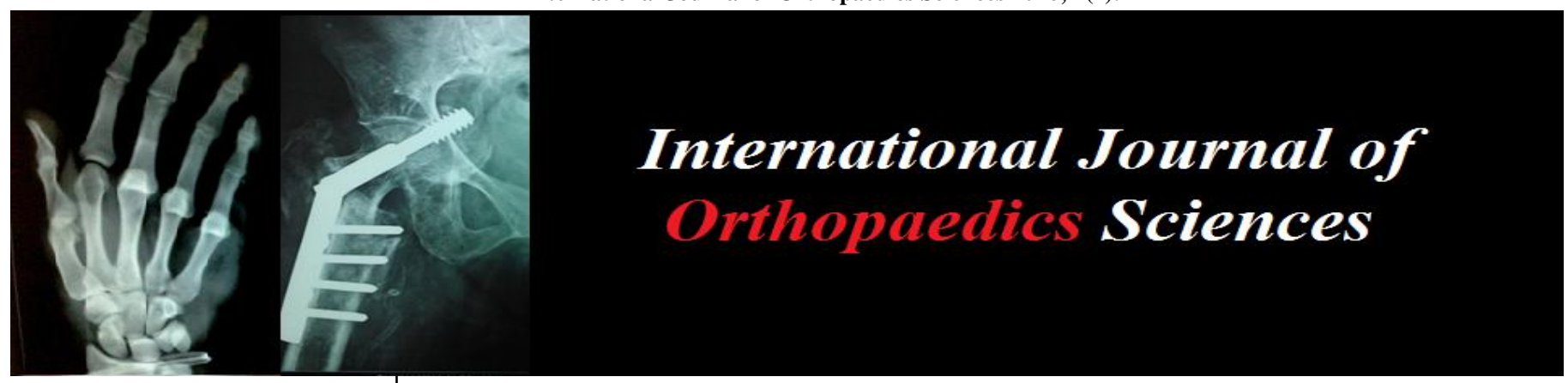

ISSN: $2395-1958$

IJOS 2016; 2(4): 424-427

(C) 2016 IJOS

www.orthopaper.com

Received: 02-08-2016

Accepted: 03-09-2016

Dr. Ramanagouda Biradar BLDE University, Shri B M Patil Medical and Research Hospital, Vijaypur, Karnataka, India

Dr. Santosh S Nandi

BLDE University, Shri B M

Patil Medical and Research

Hospital, Vijaypur, Karnataka, India

Dr. Amit Patel

BLDE University, Shri B M

Patil Medical and Research

Hospital, Vijaypur, Karnataka,

India

Dr. Arravind Pillai

BLDE University, Shri B M

Patil Medical and Research

Hospital, Vijaypur, Karnataka, India

Correspondence

Dr. Ramanagouda Biradar BLDE University, Shri B M Patil Medical and Research Hospital, Vijaypur, Karnataka, India

\section{Surgical management of displaced fractures neck of the radius in children: open reduction and temporary internal fixation in whom closed reduction has failed}

\author{
Dr. Ramanagouda Biradar, Dr. Santosh S Nandi, Dr. Amit Patel, Dr. \\ Arravind Pillai
}

DOI: http://dx.doi.org/10.22271/ortho.2016.v2.i4g.63

\begin{abstract}
Introduction: Pediatric radial neck fractures account for 5 to $10 \%$ of all elbow fractures ${ }^{[1,2]}$. The treatment of radial neck fractures in children varies according to the displacement, angulation, and skeletal maturity. Today open reduction is reserved for comminuted fractures and cases where closed reduction has failed. The purpose of this prospective study was to evaluate the outcome of open reduction and temporary internal fixation of pediatric radial neck fractures in whom initial closed reduction had failed.

Materials and Methods: This study includes 15 children with fractures of the radial neck who were treated at our hospital between Sept 2009 and Oct 2014. Fractures were classified according to the classification system described by Judet et al. Inclusion criteria were: closed, displaced radial neck fracture with an angulation of more than $30^{\circ}$ (Judet type \& III \& IV) in children with open growth plates (6-16 years) in whom closed method has failed. The patients are evaluated using MEPS score and radiograph at 2-3 month, 6 months. The patients were followed 11 to 40 months (average 18 months). The results were analysed using mean and SD deviation and ANOVA score.

Results: 15 patients with radial neck fracture treated with ORIF with temporary extra articular k wiring Technique evaluated clinically (MEPS score) and radiologically (Post op neck angle). According to MEPS score 3(20\%) had excellent results, 4(26.7\%) had good outcomes and 8(53.4\%) had fair to poor outcomes. Post op neck angle was excellent to good in $11(73.3 \%)$ patients and fair to poor in $4(26.7 \%)$ patients.

Conclusion: In the management of paediatric radial neck fracture open reduction and internal fixation should be reserved for cases where for conservative methods have failed. Open reduction is associated with poor clinical outcomes.
\end{abstract}

Keywords: Radial neck fracture, extra articular k wire, closed reduction

\section{Introduction}

Pediatric radial neck fractures account for 5 to $10 \%$ of all elbow fractures ${ }^{[1,2]}$. The treatment of radial neck fractures in children varies according to the displacement, angulation, and skeletal maturity. Most fractures are undisplaced or minimally displaced (Judet type I and II fractures) and can be treated with closed reduction and casting with good outcome [3]. However, there is a general agreement that displaced radial neck fractures with more than $30^{\circ}$ angulations (Judet type III and IV fractures) should be surgically treated ${ }^{[4,5]}$. There are several treatment possibilities for Judet type III and IV fractures, including percutaneous pin reduction ${ }^{[7]}$, elastic stable intramedullary nailing (ESIN) ${ }^{[8]}$, and open reduction with or without internal fixation ${ }^{[9]}$. The previous studies show poor functional outcome and higher complication rates following open reduction of paediatric radial neck fracture. Only the worst fractures undergo open reduction so, once again, is it the fracture or the treatment that leads to a poor outcome is not studied. Today open reduction is reserved for comminuted fractures and cases where closed reduction has failed. The purpose of the present prospective study was to evaluate the outcome of open reduction and temporary internal fixation of pediatric radial neck fractures in which initial closed reduction had failed. 


\section{Materials and Methods}

This study includes 15 children with fractures of the radial neck fracture who were treated at our hospital between Sept 2009 and Oct 2014. Fractures were classified according to the classification system described by Judet et al.

Inclusion criteria were: closed, displaced radial neck fracture with an angulation of more than $30^{\circ}$ (All are Judet type-3 and type-4) in children with open growth plates (6-16 years) in whom closed method has failed.

The time from injury to surgery ranged from 3days to 14 days. All children were initially tried by closed method and not achieved acceptable reduction. The open reduction was performed through posterolateral approach for elbow (Kocher approach). The fracture was reduced under vision and fixed with $1.5 \mathrm{~mm}$ single $\mathrm{K}$-wire. Only in two patients two $\mathrm{K}$-wires were used. All K-wires were passed from proximal fragment to distal meta or diaphyseal cortex without crossing the capitulum. The K-wire was left protruding out of the skin and was bent over to prevent migration. A long arm cast with the forearm in a neutral position was applied for three weeks. Two olecra non fractures were treated by closed reduction and fixation with single percutaneous k-wire. All children evaluated clinically and radiologically at 2 or 3 months, and thereafter at 6 monthly intervals. The follow- up period ranged from 11 to 40 months, with a mean of 18 months. All patients were called for follow up before October 2014 and radiographs and hospital records were reviewed by one of the two authors. The patients were evaluated for range of motion (ROM), radiological evaluation of alignment, functional results using the Mayo elbow performance score (MEPS), and early or late complications.

Flexion and extension of elbow, pronation and supination of the forearm and the angle of the extended elbows were measured by a goniometer. Radial head angulation was measured by the angle between the perpendicular of the axis of the displaced radial epiphysis and the long axis of the radial shaft Radiologically, the reduction was considered excellent when it healed in the anatomical position, good when the radial neck angle was less than $20^{\circ}$, medium when the angle was between $20^{\circ}$ and $40^{\circ}$, poor with an angle of more than $40^{\circ}$. The joint's stability was graded as stable, mildly unstable or unstable. The functional score is determined on the basis of the patient's ability to perform normal activities of daily living. The total score ranges from 5 to 100 points, with higher scores indicating better function. If the total score is between 90 and 100 points, it can be considered excellent outcome; between 75 and 89 points is good; between 60 and 74 points is fair and less than 60 points is poor ${ }^{[17]}$.

\section{Results}

Table 1: Gender distribution of Patients

\begin{tabular}{|c|c|c|}
\hline Gender & $\mathbf{N}$ & \% \\
\hline Male & 12 & 80.0 \\
\hline Female & 3 & 20.0 \\
\hline
\end{tabular}

In this study of all 15 patients, $12(80 \%)$ were males and $3(20 \%)$ were females

Table 2: Age distribution of Patients

\begin{tabular}{|c|c|c|c|c|c|c|}
\hline \multirow{3}{*}{ Age } & \multicolumn{2}{|c|}{ Male } & \multicolumn{2}{c|}{ Female } & \multicolumn{2}{c|}{ Total } \\
\cline { 2 - 7 } & Mean & SD & Mean & SD & Mean & SD \\
\cline { 2 - 7 } & 7.6 & 1.2 & 8.0 & 1.0 & 7.7 & 1.2 \\
\hline
\end{tabular}

In this study Mean age was 7.6 in males and 8 in females with 7.7 being the total mean.

Table 3: Distribution of Post op neck angle and MEPS SCORE

\begin{tabular}{|c|c|c|c|c|}
\hline \multirow{2}{*}{ Results } & \multicolumn{2}{|c|}{ Post op neck angle } & \multicolumn{2}{c|}{ MEPS SCORE } \\
\cline { 2 - 5 } & No. of Patients & $\%$ & No. of Patients & $\%$ \\
\hline Excellent & 5 & 33.3 & 3 & 20.0 \\
\hline Good & 6 & 40.0 & 4 & 26.7 \\
\hline Fair & 2 & 13.3 & 4 & 26.7 \\
\hline Poor & 2 & 13.3 & 4 & 26.7 \\
\hline
\end{tabular}

In the following study according to Post op neck angle 5(33\%) had Excellent results $6(40 \%)$ had Good results $2(13.3 \%)$ had Fair results and 2(3.3\%) had Poor results. According to MEPS scoring $3(20 \%)$ had excellent score $4(26.7 \%)$ had Good results $4(26.7 \%)$ had Fair results and $4(26.7 \%)$ had poor results.

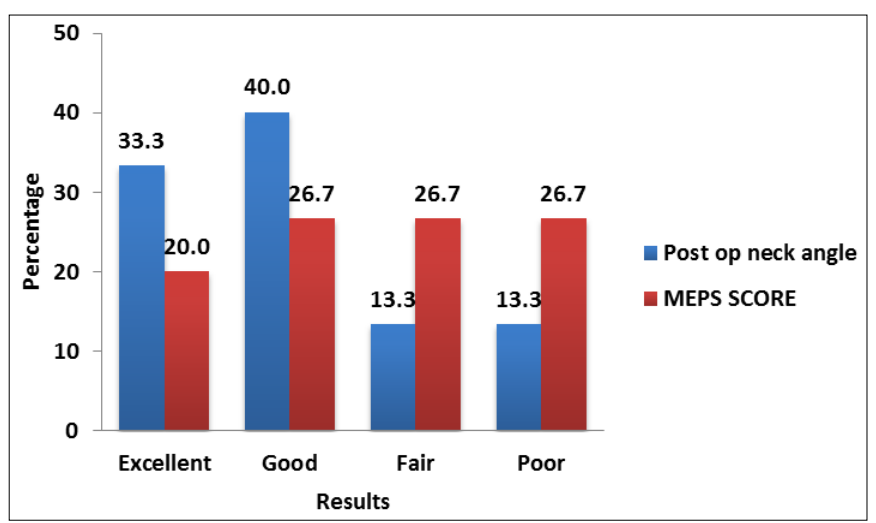

Fig 1: Distribution of Post op neck angle and MEPS SCORE

Table 4: Association between Post op neck angle and MEPS SCORE among total patients

\begin{tabular}{|c|c|c|c|c|c|c|}
\hline \multirow{2}{*}{ Post op neck angle } & \multicolumn{4}{|c|}{ MEPS Score } & \multirow{2}{*}{ Total } & \multirow{2}{*}{ Chi square $p$ value } \\
\hline & Poor & Fair & Good & Excellent & & \\
\hline Poor & 2 & 0 & 0 & 0 & 2 & \multirow{5}{*}{0.099} \\
\hline Fair & 1 & 1 & 0 & 0 & 2 & \\
\hline Good & 1 & 3 & 1 & 1 & 6 & \\
\hline Excellent & 0 & 0 & 3 & 2 & 5 & \\
\hline Total & 4 & 4 & 4 & 3 & 15 & \\
\hline
\end{tabular}

While comparing Post op neck angle and MEPS score among total patients who had poor results according to both post op neck angle and MEPS score. Of 2 patients with fair results according to post op neck angle, 1 had poor results and 1 had fair results according to MEPS score. Of 6 patients with good results according to post op neck angle, 1 had poor results, 3 had fair results, 1 had good results and 1 had excellent results according to MEPS score. Of 5 patients with Excellent results according to post op neck angle 3 had good results while 2 had excellent results according to MEPS scoring. Comparing between post op neck angle and MEPS score shows that $\mathrm{CHI}$ square $\mathrm{P}$ value (0.099) was significant. 
Table 5: Correlation between Post op neck angle and MEPS Score

\begin{tabular}{|c|c|c|c|c|}
\hline & Mean & SD & $\begin{array}{c}\text { Correlation } \\
\text { Coefficient }\end{array}$ & p value \\
\hline Post op neck angle & 16.2 & 14.1 & -0.667 & \multirow{2}{*}{0.007 (Sig) } \\
\hline MEPS SCORE & 71.0 & 19.7 & & \\
\hline
\end{tabular}

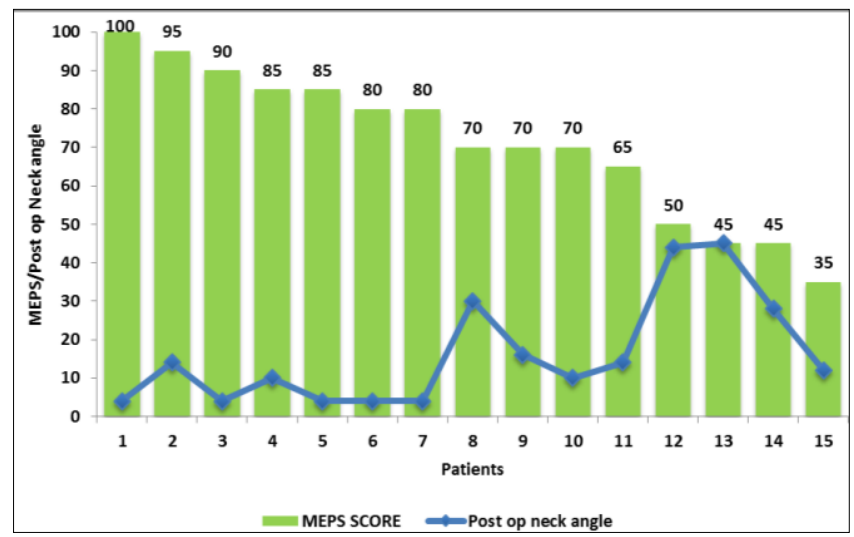

Fig 2: Association between Post op neck angle and MEPS Score

Mean for post op neck angle was 16.2 and SD was 14.1 and MEPS score mean was 71.0 and SD was 19.7 which shows that significant coefficient relation and $p$ value (0.007) was significant. It suggests that post op neck angle and MEPS score have significant strong indirect correlation score.

Table 6: Mean distribution of MEPS SCORE by Post op neck angle

\begin{tabular}{|c|c|c|c|c|c|}
\hline \multirow{2}{*}{ Post op neck angle } & \multicolumn{3}{|c|}{ MEPS Score } & \multicolumn{2}{c|}{ ANOVA } \\
\cline { 2 - 4 } & N & Mean & SD & F value & p value \\
\hline Excellent & 5 & 87.0 & 8.4 & & \\
\hline Good & 6 & 70.0 & 20.5 & \multirow{2}{*}{3.734} & \multirow{2}{*}{$0.045^{*}$} \\
\hline Fair & 2 & 57.5 & 17.7 & & \\
\hline Poor & 2 & 47.5 & 3.5 & & \\
\hline
\end{tabular}

*significant

Post op neck angle and MEPS score Mean and Standard Deviation are strongly significantly correlated.

Case 1
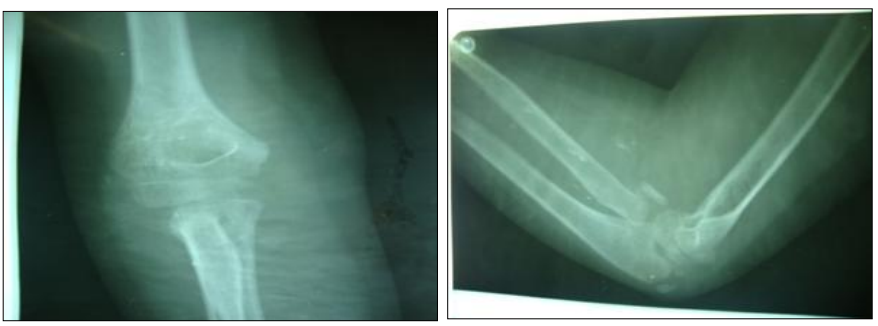

Fig 3: Pre op xray AP view \& Lateral view
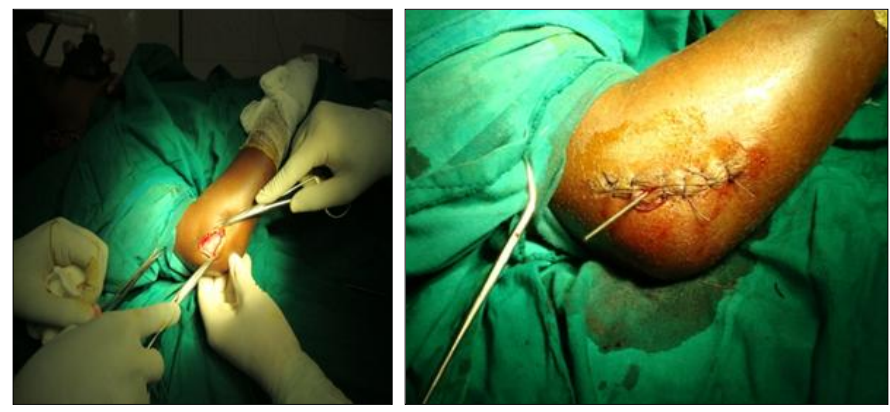

Fig 4: Intra operative images

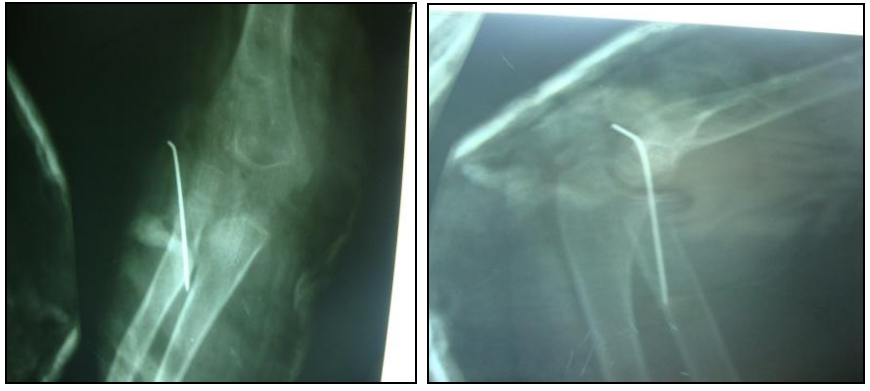

Fig 5: Post operative Ap \& Lateral images

Case 2

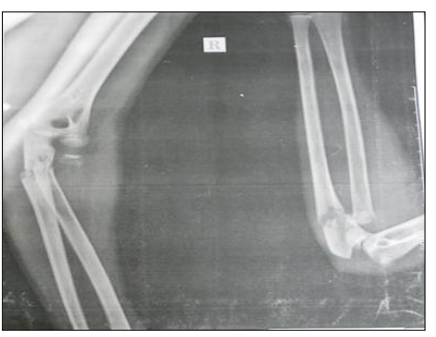

Pre op xray

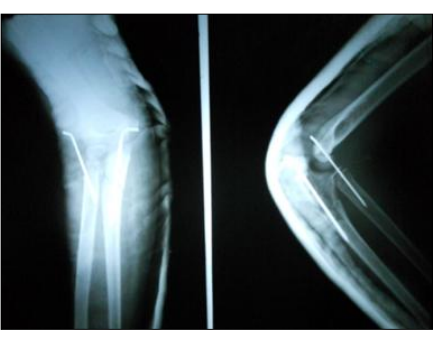

post op xray
Fig 6
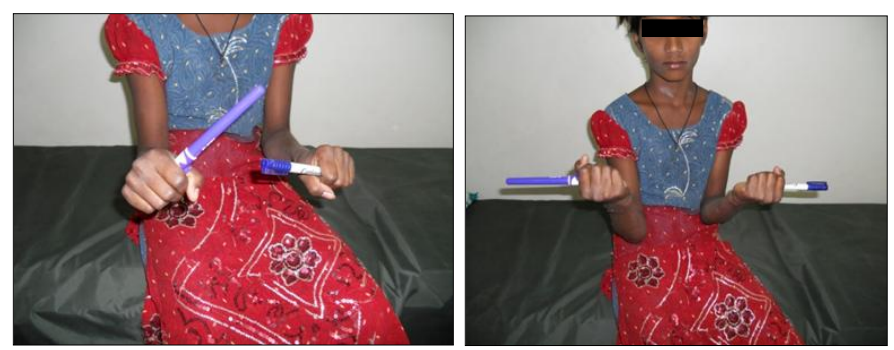

Fig 7: Clinical photograph

\section{Discussion}

This study was conducted to assess the clinical and radiographical outcomes, and complications rate in patients with displaced radial neck fractures treated with open reduction and temporary internal fixation. We agree with the majority of authors and widely reported literature that open reduction leads to worse outcomes instead of a good reduction of the fracture $[1,2,3,4]$. In this series based on the clinical evaluation criteria presented, there are $3(20 \%)$ excellent, 4 (26.6\%) good, $4(26.6 \%)$ fair and $4(26.6 \%)$ poor results. Different authors have reported wast range of poor out come following ORIF, with only excellent out come in 50\% ${ }^{[18]}$, $42 \%{ }^{[19]}, 38 \%{ }^{[20]}, 32 \%{ }^{[21]}$ and $22 \%{ }^{[22]}$ cases. Overall, however, the results from ORIF are not satisfactory. Only one in five patients has an excellent outcome, indicating that this may not be the most appropriate method to treat these difficult fractures. Less invasive reduction methods should precede open reduction whenever possible.

The open Reduction method of treatment is associated with high incidence of complications like, avascular necrosis, proximal synostosis, heterotopic ossification, infection, premature physeal closure, radial head overgrowth and loss of ROM is higher than after closed reduction $[5,2,4,6,11,12$, . Therefore less invasive methods of reduction have been developed in an effort to avoid the higher incidence of complications associated with open reduction.

However, some radial neck fractures, in particular severely displaced, are impossible to reduce with closed method and 
require open reduction $[7,8,9]$. Open reduction is inevitable in cases of comminuted fractures, interposition of the capsule or annular ligament between the head and the neck, totally displaced, and fracture dislocation ${ }^{[10]}$.

The factors which influence the final outcome of the radial neck fracture are age of the child, greater initial fracture displacement, time to surgery of two days or less, associated injuries, open treatment and residual angulation may contribute to poor outcomes.

Age is also a good predictor for the long-term result. The remodelling process varies with the age of the patient. The young children have greater remodelling potential and hence greater degrees of residual angulation can be accepted ${ }^{[13,14]}$. However, the proximal physis of the radius is responsible for only $20-30 \%$ of the growth of the radius and therefore spontaneous fracture remodeling is restricted.

Many controversies may be found in the literature with respect to what should be considered an acceptable reduction. While $30^{\circ}$ or more angulation is widely considered an indication for reduction, some argue that residual angulation of $45^{\circ}$ after closed reduction is acceptable ${ }^{[15]}$, citing the risks of open reduction. Others, however, urge surgeons to "not hesitate to operate on the displaced fracture and reduce it into an anatomic position" if closed treatment fails ${ }^{[16]}$.

The definitions of open surgery vary as well, with some authors warning that "open reduction should be avoided if at all possible," [17] and others stating that "whenever possible, internal fixation should be avoided." [15] Is it the open reduction, the internal fixation, or the severity of the fracture or iatrogenic trauma of manipulation that predisposes the patient to a poor result is not clear and no controlled studies are available. Also only the wrost fractures will go for open reduction and hence

In most published studies, concomitant injuries were associated with unfavourable results. ${ }^{[1,14,20,21,22]}$. In this series two patients had olecranon fracture and both had poor outcome.

\section{Conclusion}

In the management of paediatric radial neck fracture open reduction and internal fixation should be reserved for cases where for conservative methods have failed. Open reduction is associated with poor clinical outcomes.

\section{References}

1. Steele JA, Graham HK. Angulated radial neck fractures in children. A prospective study of percutaneous reduction. J Bone Joint Surg Br. 1992; 74:760-764.

2. Waters PM, Stewart SL. Radial neck fracture nonunion in children. J Pediatr Ortho. 2001; 21:570-576.

3. Me'taizeau JP. Reduction and osteosynthesis of radial neck fractures in children by centromedullary pinning. Injury. 2005; 36(Suppl 1):A75-A77.

4. Tibone JE, Stoltz M. Fractures of the radial head and neck in children. J Bone Joint Surg Am. 1981; 63:100-106.

5. Newman JH. Displaced radial neck fractures in children. Injury. 1977; 9(2):114-121.

6. Young S, Letts M, Jarvis J. Avascular necrosis of the radial head in children. J Pediatr Ortho. 2000; 20(1):15-18

7. Steinberg EL, Golomb D, Salama R, Wientroub S. Radial head and neck fractures in children. J Pediatr Ortho. 1988; 8(1):35-40.

8. Fowles JV, Kassab MT. Observations concerning radial neck fractures in children. J Pediatr Ortho. 1986; 6(1):5157.
9. Pesudo JV, Aracil J, Barcelo M. Leverage method in displaced fractures of the radial neck in children. Clin Orthop Relat Res. 1982; 169:215-218.

10. Schmittenbecher PP, Haevernick B, Herold A, Knorr P, Schmid E. Treatment decision, method of osteosynthesis, and outcome in radial neck fractures in children: a multicenter study. J Pediatr Ortho. 2005; 25(1):45-50.

11. Steele JA, Graham HK. Angulated radial neck fractures in children. A prospective study of percutaneous reduction. J Bone Joint Surg. 1992; 74(B):760-764.

12. Tollet PH, Toussaint D, Djemal C et al. Traitement chirurgical des fractures du col radial chez l'enfant par la technique de Métaizeau. Acta Orthop Belg. 1997; 63:245249.

13. Bernstein SM, Mc Keever P, Bernstein. Percutaneous reduction of displaced radial neck fractures in children.

14. Metaizeau JP, Lascombes P, Lemelle JL et al. Reduction band fixation of displaced radial neck fractures by closed intramedullary pinning. J Pediatr Orthop. 1993; 13:355360.

15. Erickson M, Frick S. Fractures of the proximal radius and ulna. In: Beaty JH, Kasser JR, editors. Rockwood and Wilkins' fractures in children. 7th ed. Philadelphia: Lippincott Williams \& Wilkins. 2010, 405-45.

16. Green NE, Van Zeeland NL. Fractures and dislocations about the elbow. In: Green NE, Swiontkowski MF, editors. Skeletal trauma in children. 4th ed. Philadelphia: Saunders. 2009, 207-82.

17. Frances JM, Cornwall R. Closed percutaneous and open reduction of radial head and neck fractures. In: Wiesel SW, editor. Operative techniques in orthopaedic surgery. Philadelphia: Lippincott Williams \& Wilkins. 2011, 105865.

18. Vocke AK, von Laer L. Displaced fractures of the radial neck in children: long-term results and prognosis of conservative treatment. J Pediatr Orthop B. 1998; 7:21722.

19. Steinberg EL, Golomb D, Salama R, Wientroub S. Radial head and neck fractures in children. J Pediatr Ortho. 1988; 8:35-40.

20. Vahvanen V, Gripenberg L. Fracture of the radial neck in children. Acta Orthop Scand. 1978; 49:32-8.

21. Tibone JE, Stoltz M. Fractures of the radial head and neck in children. J Bone Joint Surg [Am]. 1981; 63(A):100-6.

22. Fowles JV, Kassab MT. Observations concerning radial neck fractures in children. J Pediatr Orthop. 1986; 6:51-7. 